Paper

\title{
Dependence of Fluorescence Spectra of Susabi-nori (Porphyra yezoensis) on the Excitation Wavelength
}

\author{
Tamotsu OKAMOTO*, Atsushi TAKATAMA*, Kazuki MURATA*, Yuko OHNO-KAKAZU**, \\ Kunio TAKAHASHI ${ }^{* *}$, Toshihiro HAYASHI ${ }^{* * *}$, Yushi SHIMADA ${ }^{* * *}$ and Shohei KANEKO *** \\ * Kisarazu National College of Technology, Department of Electrical and Electronic Engineering \\ ** Kisarazu National College of Technology, Division of Natural Science Education \\ *** Chiba Prefectural Fisheries Research Center, Tokyo Bay Fisheries Laboratory
}

Received March 17, 2010, Accepted July 20, 2010

\begin{abstract}
This research paper aims to investigate dependence of fluorescence spectra of Susabi-nori (Porphyra yezoensis) on the excitation wavelength by comparing with absorption spectra of photosynthetic pigments. The intensities of the fluorescent peaks located at approximately $685 \mathrm{~nm}$ and $720 \mathrm{~nm}$ relatively increased by using the excitation light with the wavelength of approximately $430 \mathrm{~nm}$, because the excitation light was mostly absorbed by chlorophyll-a. On the other hand, the intensity of the $580 \mathrm{~nm}$ peak relatively increased by using that of approximately $500 \mathrm{~nm}$, because the excitation light was mostly absorbed by phycoerythrin. As a result, the intensity ratio of the $580 \mathrm{~nm}$ peak to the 685 $\mathrm{nm}$ peak was maximal at the excitation wavelength of approximately $500 \mathrm{~nm}$. Therefore, it was concluded that the optimum excitation wavelength was approximately $500 \mathrm{~nm}$ for diagnosis of diseases and stresses of Susabi-nori.
\end{abstract}

KEYWORDS: Susabi-nori, Porphyra yezoensis, laser-induced fluorescence, red rot disease

\section{Introduction}

In the conventional nori (laver; Porphyra) cultivation, fishermen diagnose the influences of diseases and stresses by means of the visual inspection or the optical-microscope observation. However, a quantitative evaluation technique is required for more stable nori production. In addition, diagnosis technique is also required in the early stage when diagnosis of nori is impossible by the visual inspection or the optical-microscope observation.

Up until now, we have proposed the laser-induced fluorescence (LIF) method for diagnosis of Susabi-nori (Porphyra yezoensis), and revealed that fluorescence spectra of Susabi-nori were affected by the diseases and the stresses of fresh water and that the diseases and the stresses of Susabi-nori could be diagnosed by the fluorescence method ${ }^{1}$. However, the fluorescence mechanisms are not clear yet.

In this work, we investigated the dependence of fluorescence spectra of Susabi-nori on the excitation wavelength by comparing with absorption spectra of photosynthetic pigments.

\section{Materials and methods}

The samples of Susabi-nori were cultivated from October to December, 2007 by Kaneda fisheries cooperative and Shin-Futtsu fisheries cooperative, Chiba prefecture, Japan. The fluorescence spectra were measured immediately after gathering these samples.
In order to investigate the dependence of fluorescence spectra on the excitation wavelength, a Xe lamp (L6759, Hamamatsu Photonics, Japan) was used as an excitation light. The Xe-lamp light was monochromated by a monochromator (H20 IR, Horiba Jobin Yvon, France). The intensity of the monochromatated Xe-lamp light ranged from 15 to $100 \mu \mathrm{W} / \mathrm{cm}^{2}$. The laser lights with wavelengths of $325 \mathrm{~nm}$ (cw He-Cd laser, IK3301R-G-S, Kimmon, Japan, $10 \mathrm{~mW}$ ), $375 \mathrm{~nm}$ (cw laser diode, LDM375.10CW, Omicron, Germany, $190 \mu \mathrm{W}$ ), $405 \mathrm{~nm}$ (cw laser diode, 405-50-COL 003, Oxxius, France, $10 \mathrm{~mW}$ ) and $488 \mathrm{~nm}\left(\mathrm{cw} \mathrm{Ar}{ }^{+}\right.$laser, GLG3020, NEC, Japan, $6 \mathrm{~mW}$ ) were also used as excitation lights for comparison. The fluorescence spectra were measured in sea water at approximately $20^{\circ} \mathrm{C}$, and analyzed using a multichannel monochromator (PMA-12, Hamamatsu Photonics, Japan). The quantity of the sea water was so limited that it had little influence on the fluorescence measurement of Susabi-nori. The fluorescence was guided to the monochromator using the optical fiber. The short-wavelength cut-off filter under 530 $\mathrm{nm}$ was attached to the optical fiber in order to prevent the influence of the excitation light.

\section{Results and discussion}

Figure 1 and 2 show the dependences of fluorescence spectrum of Susabi-nori on the excitation wavelength by using the monochromated Xe-lamp lights and the lasers, respectively. As reported in the previous paper, the 


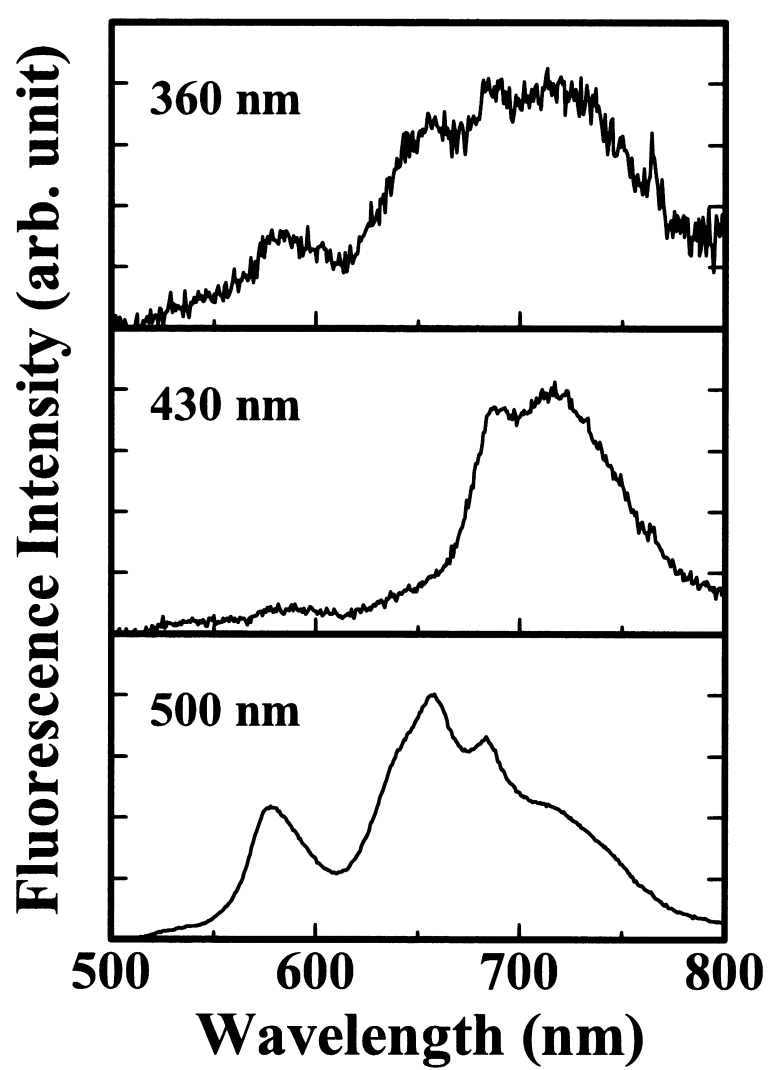

Figure 1 Dependence of fluorescence spectrum on the excitation wavelength by using the monochromated Xe-lamp lights

fluorescent peaks located at approximately 580, 660, 685 and $720 \mathrm{~nm}$ were observed in the spectra ${ }^{1}$. The emissions at approximately $580 \mathrm{~nm}$ and $660 \mathrm{~nm}$ probably originate in phycoerythrin and allophycocyanin, respectively2), and those at approximately $685 \mathrm{~nm}$ and $720 \mathrm{~nm}$ are probably due to chlorophyll- $\mathrm{a}^{3}$. Distinctive individual differences were not observed in terms of intensity ratio of each peak. As shown in Figure1, the fluorescence spectra were clearly observed even by using the monochromated Xe-lamp lights. From these figures, it was found that the fluorescence intensity ratios such as the ratio of the 580 $\mathrm{nm}$ peak to the $685 \mathrm{~nm}$ peak were affected by the excitation wavelength.

Figure 3 shows the dependence of the fluorescence intensity ratio of the $580 \mathrm{~nm}$ peak to the $685 \mathrm{~nm}$ peak (F580/F685 ratio) on the excitation wavelength by using the monochromated Xe-lamp lights and the lasers, and the reported absorption spectra of photosynthetic pigments $\left.{ }^{4}\right)^{-7}$. The vertical dashed lines denote the

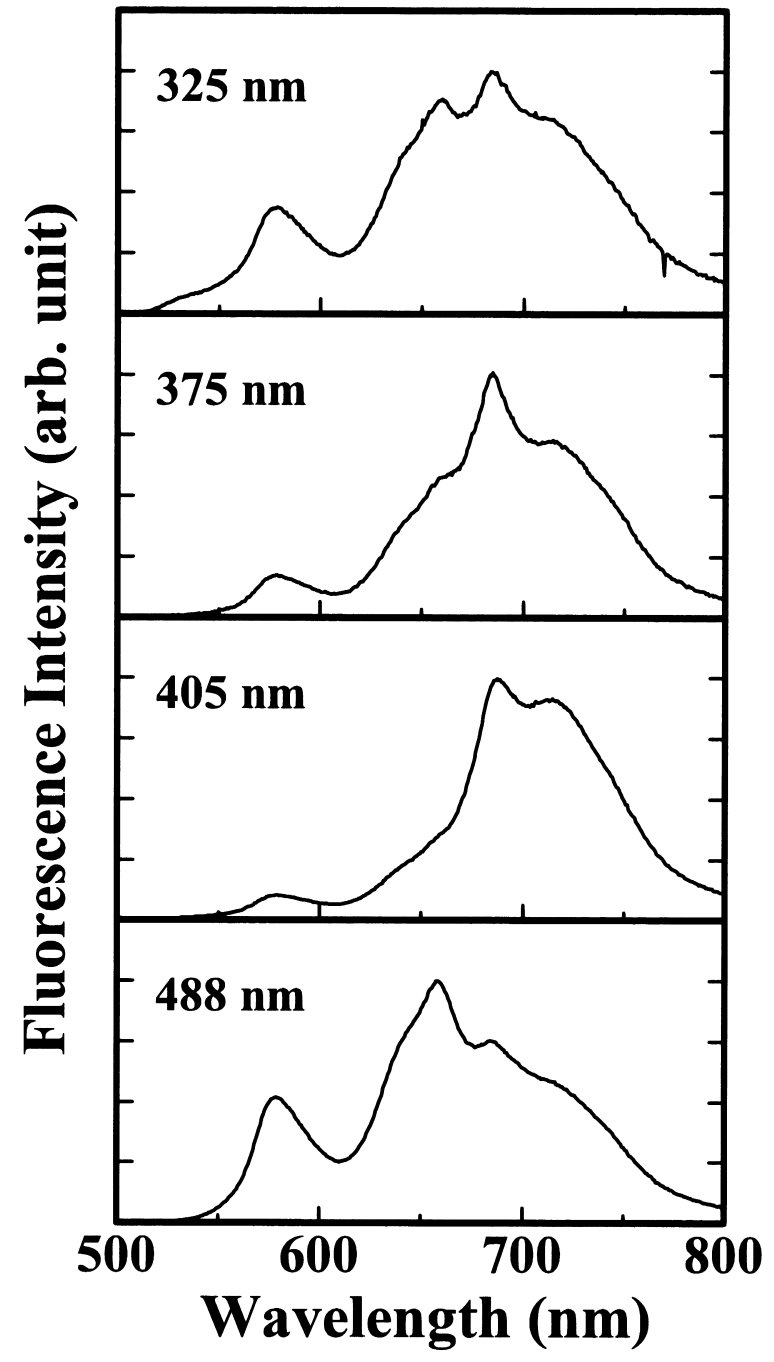

Figure 2 Dependence of fluorescence spectrum on the excitation wavelength by using the lasers

wavelengths of 430 and $500 \mathrm{~nm}$, at which the absorbances were maximal in chlorophyll-a and R-phycoerythrin, respectively. It was found that the F580/F685 ratio was minimal at the excitation wavelength of approximately $430 \mathrm{~nm}$. The $685 \mathrm{~nm}$ peak probably originates in chlorophyll-a, and the absorbance of the chlorophyll-a is maximal at the wavelength of approximately $430 \mathrm{~nm}$. Therefore, this result suggests that the $685 \mathrm{~nm}$ peak intensity relatively increases by using the excitation light with the wavelength of approximately $430 \mathrm{~nm}$, because the excitation light is mostly absorbed by chlorophyll-a. On the other hand, the F580/F685 ratio increased at the excitation wavelength of approximately $500 \mathrm{~nm}$. The 580 $\mathrm{nm}$ peak probably originates in phycoerythrin, and the absorbance of the phycoerythrin is high at the wavelength of approximately $500 \mathrm{~nm}$. Therefore, this result indicates that the $580 \mathrm{~nm}$ peak intensity relatively increases by using the excitation light with the wavelength of approximately $500 \mathrm{~nm}$, because the excitation light is mostly absorbed by phycoerythrin. 


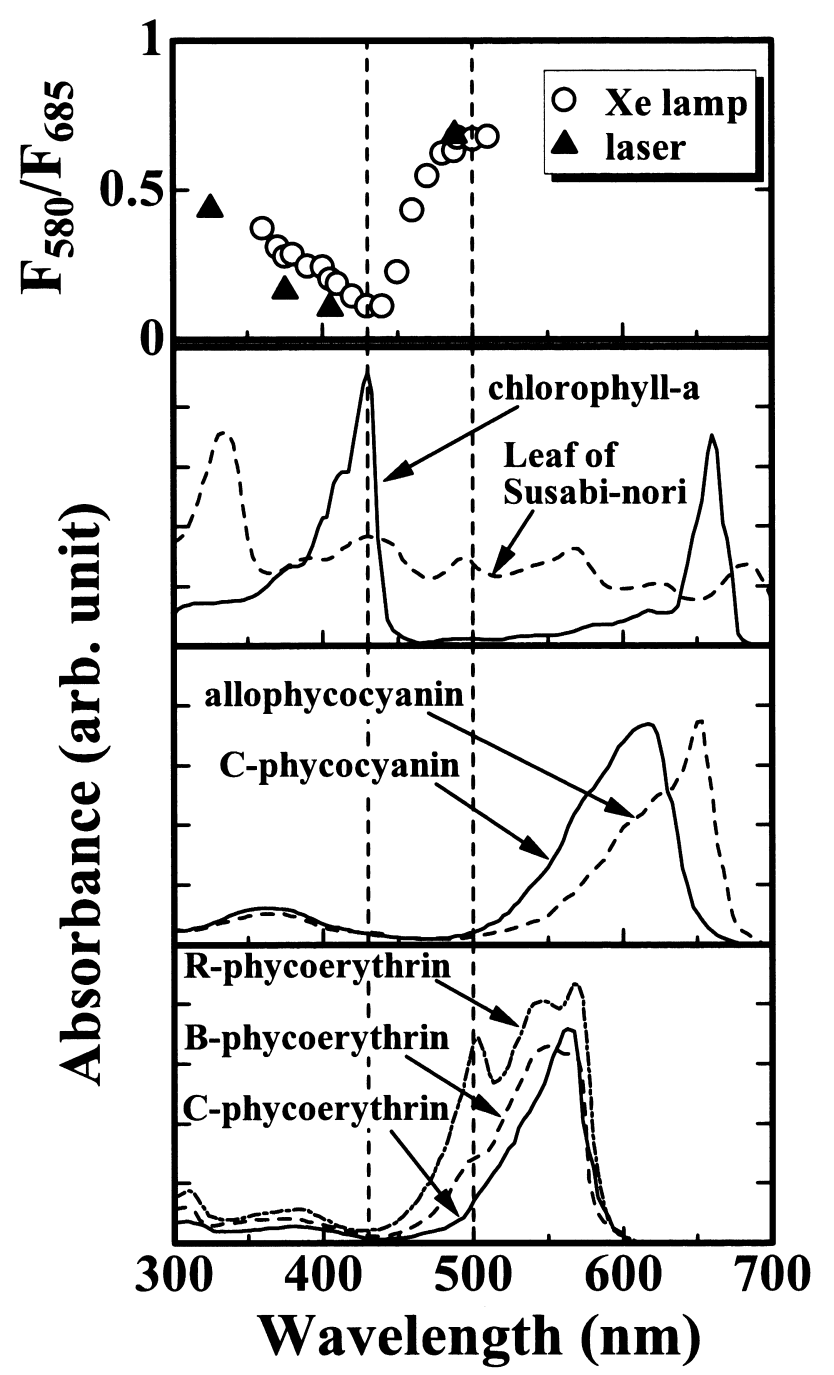

Figure 3 Dependence of the intensity ratio of the 580 $\mathrm{nm}$ peak to the $685 \mathrm{~nm}$ peak on the excitation wavelength and absorption spectra of the photosynthetic pigments ${ }^{4-7)}$

Figure 4 shows the dependence of the intensities of the peaks located at approximately $580 \mathrm{~nm}$ (F580), $660 \mathrm{~nm}$ (F660), $685 \mathrm{~nm} \mathrm{(F685)} \mathrm{and} 720 \mathrm{~nm} \mathrm{(F720),} \mathrm{and} \mathrm{the}$ integrated intensity between 530 to $800 \mathrm{~nm}$ on the excitation wavelength by using the monochromated Xelamp lights. The integrated intensities were the integral of the fluorescence intensity from 530 to $800 \mathrm{~nm}$. In the measurement system, the intensities of the monochromated Xe-lamp lights varied with the wavelength. Therefore, the intensities of the fluorescent peaks were confirmed to be proportional to the excitationlight intensity in preliminary experiment, and the fluorescence intensity at each wavelength was revised after divided by the excitation-light intensity in order to remove the variance influences in the excitation-light intensity. At the excitation wavelength of approximately $430 \mathrm{~nm}$, the intensities of the 580 and $660 \mathrm{~nm}$ peaks were

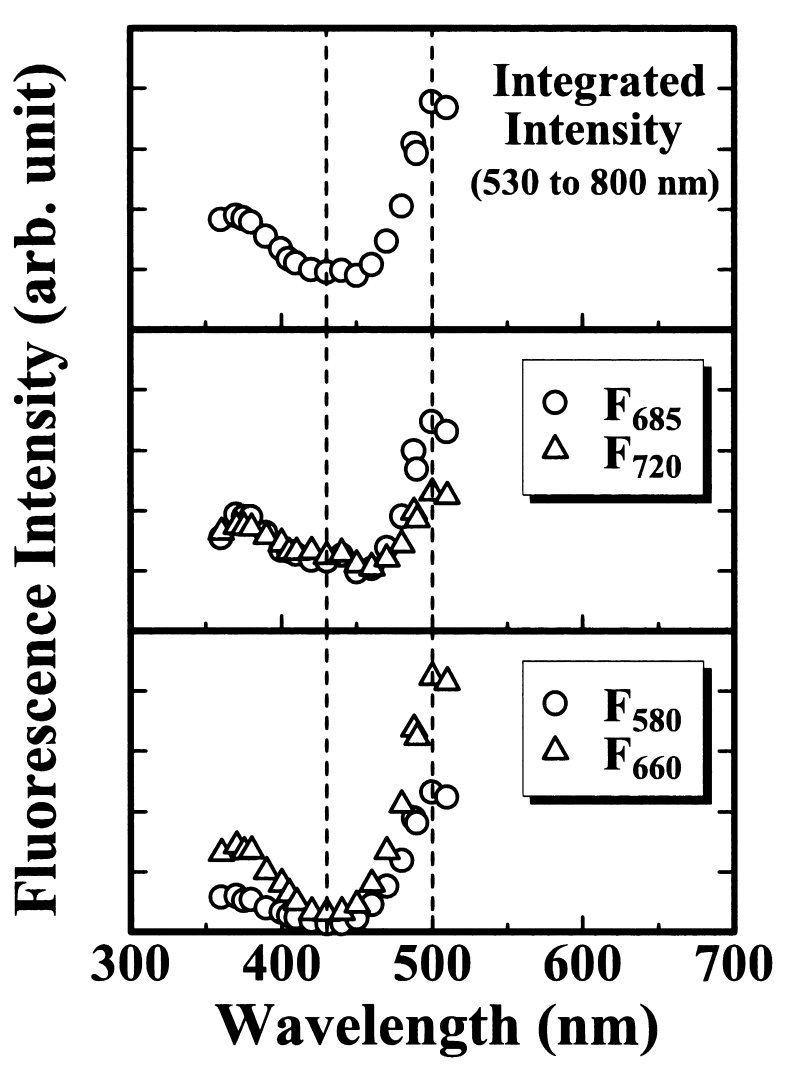

Figure 4 Dependence of the intensities of the 580, 660, 685 and $720 \mathrm{~nm}$ peaks and the integrated intensity between 530 to $800 \mathrm{~nm}$ on the excitation wavelength

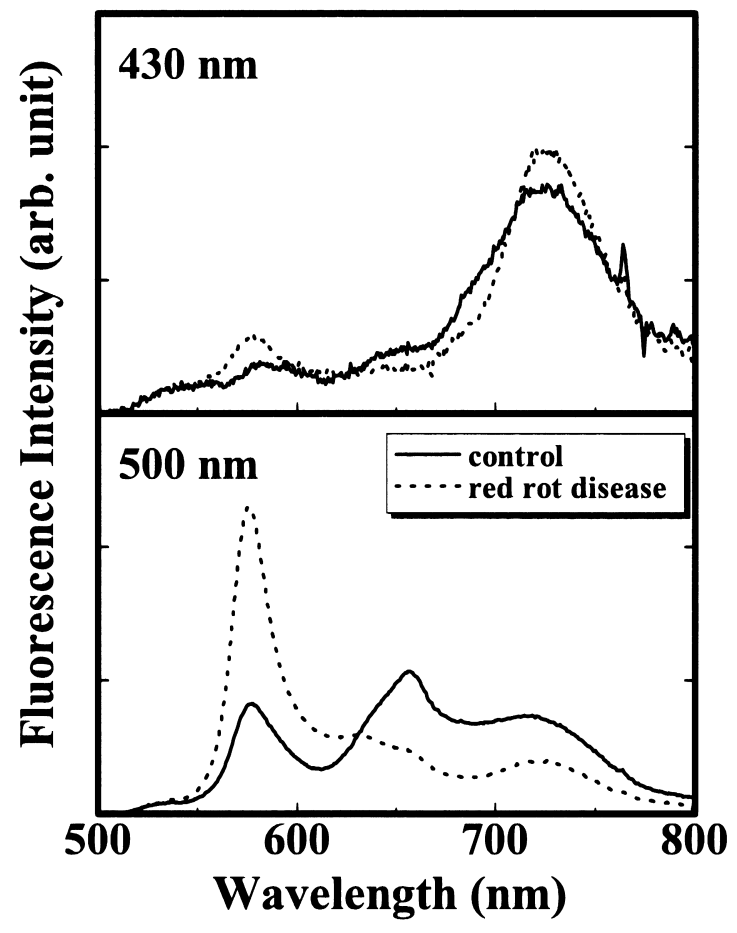

Figure 5 Fluorescence spectra of the control sample and the sample infected with the red rot disease by using the excitation lights with wavelengths of 430 and $500 \mathrm{~nm}$ 
very weak, because the excitation light with the wavelength of approximately $430 \mathrm{~nm}$ was mostly absorbed by chlorophyll-a. On the other hand, the intensities of any peaks were maximal at the excitation wavelength of approximately $500 \mathrm{~nm}$. The excitation light with the wavelength of approximately $500 \mathrm{~nm}$ was mostly absorbed by phycoerythrin, but the energy absorbed by phycoerythrin was transferred to chlorophyll-a as a photosynthetic reaction center. Therefore, the intensities of the 685 and $720 \mathrm{~nm}$ peaks, which probably originated in chlorophyll-a, increased by using the excitation light with the wavelength of approximately $500 \mathrm{~nm}$. Moreover, the integrated intensity between 530 to $800 \mathrm{~nm}$ was the minimum at the excitation wavelength of approximately $430 \mathrm{~nm}$, and was greatly increased near the excitation wavelength of $500 \mathrm{~nm}$. This result indicates that the fluorescence yield is low at the excitation wavelength of $430 \mathrm{~nm}$, at which most photons are absorbed by chlorophyll-a as a photosynthetic reaction center.

Furthermore, we investigated the dependence of the fluorescence spectrum of Susabi-nori infected with the red rot disease on the excitation wavelength. Figure 5 shows fluorescence spectra of the control sample and the sample infected with the red rot disease by using the excitation lights with wavelengths of 430 and $500 \mathrm{~nm}$. At the excitation wavelength of $500 \mathrm{~nm}$, the F580/F685 intensity ratio distinctly increased by the effect of the red rot disease as reported in the previous paper ${ }^{11}$. On the other hand, the difference between the fluorescence spectrum of the control sample and that of the sample infected with the red rot disease was not clear at the excitation wavelength of $430 \mathrm{~nm}$, because the intensities of the 580 $\mathrm{nm}$ peak were very weak. We reported that the F580/F685 intensity ratio was useful to the evaluation of diseases and stresses in Susabi-nori1). Therefore, we concluded that the optimum excitation wavelength was approximately $500 \mathrm{~nm}$ for diagnosis of diseases and stresses of Susabi-nori.

\section{Conclusions}

We investigated dependence of fluorescence spectra of Susabi-nori (Porphyra yezoensis) on the excitation wavelength by comparing with absorption spectra of photosynthetic pigments. It was found that the intensity ratio of the $580 \mathrm{~nm}$ peak to the $685 \mathrm{~nm}$ peak was maximal at the excitation wavelength of approximately $500 \mathrm{~nm}$. Furthermore, we investigated the dependence of the fluorescence spectrum of Susabi-nori infected with the red rot disease on the excitation wavelength, and it was found that the intensity ratio of the $580 \mathrm{~nm}$ peak to the $685 \mathrm{~nm}$ peak distinctly increased by the effect of the red rot disease at the excitation wavelength of $500 \mathrm{~nm}$. Therefore, we concluded that the optimum excitation wavelength was approximately $500 \mathrm{~nm}$ for diagnosis of diseases and stresses of Susabi-nori.

\section{Acknowledgments}

This work was supported in part by a Grant-in-Aid for Scientific Research (C) from the Japan Society for the Promotion of Science (JSPS), No.18580196, and also by a grant from the Futaba Electronics Memorial Foundation, Chiba, Japan. The authors would like to thank Kaneda fishery cooperative and Shin-Futtsu fisheries cooperative, Chiba prefecture, Japan for supplying the samples of Susabi-nori and their constructive discussions.

\section{References}

(1) Okamoto, T., Nakamura, Y., Takahashi, K., Kaneko, S. and Shimada, Y.: Diagnostics of Susabi-nori (Porphyra yezoensis) by laser-induced fluorescence method, J. Light \& Vis. Env., Vol. 32, pp. 345-348 (2008).

(2) Glazer, A. N.: Light harvesting by phycobilisomes, Ann. Rev. Biophys. Biophys. Chem., Vol. 14, pp. $47-77$ (1985).

(3) Saito, Y., Kurihara, K., Takahashi, H., Kobayashi, F., Kawahara, T., Nomura, A. and Takeda, S.: Remote estimation of the chlorophyll concentration of living trees using laser-induced fluorescence image lidar, Optical Review, Vol. 9, pp. 37-39 (2002).

(4) Notoya, M.: Nori toiu ikimono (Living being called Nori), Seizando-shoten Publishing, p. 81 (2002) (in Japanese).

(5) Katoh, S.: Kogosei nyumon (Introduction to photosynthesis), Kyoritsu Syuppan, p. 27 (1973) (in Japanese).

(6) Oishi, K: Kaiso no kagaku (Science of seaweed), Asakura Publishing, p. 18 (1993) (in Japanese).

(7) Aruga, Y.: Susabi-nori no shikisai to shikiso (Colors and pigments of Susabi-nori), Iden, Vol. 34 (9), pp. 8-13 (1980) (in Japanese). 